\title{
INFÂNCIA, CONHECIMENTO E FUNÇÃO DOCENTE NOS DOCUMENTOS DO MEC DESTINADOS A EDUCAÇÃO INFANTIL: uma análise a luz da psicologia histórico-cultural
}

\author{
Janaina Cassiano Silva ${ }^{1}$ \\ Alessandra Arce ${ }^{2}$ \\ Universidade Federal de São Carlos - UFSCar
}

\section{RESUMO}

Neste ensaio pretendemos analisar a concepção de infância, conhecimento e função docente presente nos documentos oficiais do Ministério da Educação, trazendo o modelo de Psicologia dominante neste cenário. Além disso, faremos uma reflexão pautada na Psicologia Histórico-Cultural visando contribuir para o processo de consolidação da Educação Infantil como segmento educacional promotor do desenvolvimento humano integral. Visto que, apesar dos avanços na legislação brasileira no atendimento das crianças de 0 a 6 anos, principalmente após a promulgação da Lei de Diretrizes e Bases da Educação Nacional (LDB) em 1996 e dos Referenciais Curriculares Nacionais para a Educação Infantil em 1998, ainda se verifica que o trabalho nas instituições de Educação Infantil está pautado, essencialmente, no cuidado com as crianças e o trabalho educativo muitas vezes não ocorre. Os documentos analisados publicados pelo Ministério da Educação serão: Referencial Curricular Nacional para a Educação Infantil; Parâmetros Nacionais de Qualidade para a Educação Infantil e a Política Nacional de Educação Infantil: pelo direito das crianças de zero a seis anos à Educação.

Palavras-chave: Educação Infantil. Políticas Públicas. Psicologia Histórico-Cultural.

\section{CHILDHOOD, KNOWLEDGE AND TEACHERS EDUCATION IN DOCUMENTS OF THE MEC FOR EARLY CHILDHOOD EDUCATION: an analysis based on historical-cultural psychology}

\begin{abstract}
The aim of this article is to analyze the conceptions of childhood, knowledge and teachers education in government documents for early childhood education in order to apprehend psychological models that are hegemonic. Furthermore the article also discuss the contributions of soviet psychologie for early childhood education as the first step for human integral development. The documents analyzed in this article are: Referencial Curricular Nacional para a Educação Infantil; Parâmetros Nacionais de Qualidade para a Educação Infantil e a Política Nacional de Educação Infantil: pelo direito das crianças de zero a seis anos à Educação.
\end{abstract}

Key-words: Early Childhood Education - Soviet Psychologie - Educational Policies

\section{Introdução}

O presente ensaio apresenta o fruto das discussões das pesquisas concluídas e em andamento investigadas por nós ao longo de nossa formação acadêmica, com financiamento da FAPESP. O objetivo é aprofundar a reflexão acerca da Educação Infantil, a visão do assistencialismo x ensino e demais discussões em voga no momento, além de contribuir para o processo de consolidação da Educação Infantil como segmento 
educacional promotor do desenvolvimento humano em suas máximas potencialidades para todos os indivíduos, desde a infância.

Deste modo, inicialmente, apresentaremos a concepção de infância, conhecimento e a função docente presente em alguns documentos publicados pelo Ministério da Educação para a Educação Infantil, a saber: Referencial Curricular Nacional para a Educação Infantil (BRASIL, 1998); Parâmetros Nacionais de Qualidade para a Educação Infantil (BRASIL, 2006a) e Política Nacional de Educação Infantil: pelo direito das crianças de zero a seis anos à Educação (BRASIL, 2006b). Posteriormente, discutiremos o modelo de Psicologia dominante nesses documentos, a Psicologia Tradicional, e faremos uma crítica calcada na Psicologia Histórico-Cultural.

\section{A Concepção de Infância nos Documentos Oficiais do Ministério da Educação.}

O Referencial Curricular Nacional para a Educação Infantil (RCNEI) foi desenvolvido com o objetivo de servir como um guia de reflexão sobre objetivos, conteúdos e orientações didáticas para os profissionais que atuam diretamente com crianças de 0 a 6 anos, respeitando seus estilos pedagógicos e a diversidade cultural brasileira. Ele é fruto de um amplo debate nacional, do qual participaram professores e diversos especialistas. O Referencial é composto por três volumes. O primeiro volume é nomeado de Introdução e apresenta uma reflexão sobre creches e pré-escolas no Brasil, além de situar e fundamentar concepções de criança, de educação, de instituição e do educador infantil, que foram utilizadas para definir os objetivos gerais da educação infantil, além de auxiliar na orientação da organização dos outros dois volumes. O volume 2: Formação Pessoal e Social contém o eixo de trabalho que favorece, prioritariamente, os processos de construção da Identidade e Autonomia das crianças. E, por fim, o volume 3, intitulado Conhecimento de Mundo apresenta seis documentos relativos aos eixos de trabalho orientados para "a construção das diferentes linguagens pelas crianças e para as relações que estabelecem com os objetos de conhecimento, sendo estes: Movimento, Música, Artes Visuais, Linguagem Oral e Escrita, Natureza e Sociedade e Matemática" (BRASIL, 1998, 1v, p.07). Destacaremos neste documento elementos que nos auxiliem a compreender a concepção de infância contida nele.

O Referencial apresenta a criança como sujeito histórico e social; com capacidades próprias de agir e pensar o mundo, que utiliza diferentes linguagens no processo de construção do conhecimento, sendo a aquisição deste um trabalho de criação, significação e ressignificação.

\footnotetext{
A criança como todo ser humano é um sujeito social e histórico e faz parte de uma organização familiar que está inserida em uma sociedade, com uma determinada cultura, em um determinado momento histórico. É profundamente marcada pelo meio social em que se desenvolve, mas também o marca. (BRASIL, 1998, 1v, p. 21-22).
}

Ademais, o documento ressalta que uma criança saudável é aquela capaz de aproveitar e desenvolver seu potencial biológico, emocional e cognitivo em um dado momento histórico e em dada cultura. Ou seja:

A promoção do crescimento e do desenvolvimento saudável das crianças na instituição educativa está baseada no desenvolvimento de todas as atitudes e procedimentos que atendem as necessidades de afeto, alimentação, segurança e integridade corporal e psíquica durante o 
período do dia em que elas permanecem na instituição (BRASIL, 1998, $1 \mathrm{v}$, p. 50-51)

O RCNEI traz oito capacidades que as crianças devem desenvolver a partir da organização da prática da educação infantil, sendo que estas se relacionam à imagem que a criança tem de si mesma; ao vínculo estabelecido com os adultos; ao estabelecimento e ampliação das relações sociais; à observação e exploração do meio ambiente que a circunda; ao brincar; à utilização de diferentes linguagens e ao conhecimento de diferentes culturas. Segue a descrição apresentada no documento para cada item:

1) desenvolver uma imagem positiva de si, atuando de forma cada vez mais independente, com confiança em suas capacidades e percepção de suas limitações;

2) descobrir e conhecer progressivamente seu próprio corpo, suas potencialidades e seus limites, desenvolvendo e valorizando hábitos de cuidado com a própria saúde e bem-estar;

3) estabelecer vínculos afetivos e de troca com adultos e crianças, fortalecendo sua auto-estima e ampliando gradativamente suas possibilidades de comunicação e interação social;

4) estabelecer e ampliar cada vez mais as relações sociais, aprendendo aos poucos a articular seus interesses e pontos de vista com os demais, respeitando a diversidade e desenvolvendo atitudes de ajuda e colaboração;

5) observar e explorar o ambiente com atitude de curiosidade, percebendo-se cada vez mais como integrante, dependente e agente transformador do meio ambiente e valorizando atitudes que contribuam para sua conservação;

6) brincar, expressando emoções, sentimentos, pensamentos, desejos e necessidades;

7) utilizar diferentes linguagens (corporal, musical, plástica, oral e escrita) ajustadas às diferentes intenções e situações de comunicação, de forma a compreender e ser compreendido, expressar suas ideias, sentimentos, necessidades e desejos e avançar no seu processo de construção de significados, enriquecendo cada vez mais sua capacidades expressiva;

8) conhecer algumas manifestações culturais, demonstrando atitudes de interesse, respeito e participação frente a elas e valorizando a diversidade (BRASIL, 1998, 1v, p.63).

Portanto, percebemos que a criança é considerada, no documento, como produtora de cultura, que utiliza diferentes linguagens no processo de construção do conhecimento e que é detentora de saberes próprios.

OS Parâmetros Nacionais de Qualidade para a Educação Infantil (BRASIL, 2006a) lançados após o RCNEI referendam, do ponto de vista da concepção de infância o que apresentamos acima. Este documento apresenta como objetivo estabelecer padrões de referência orientadores para o sistema educacional no que tange a organização e funcionamento das instituições de Educação Infantil. Ademais, este material pretende delimitar parâmetros de qualidade suficientemente amplos para abranger diferenças regionais, flexíveis para possibilitar que as manifestações culturais locais tenham espaço para se desenvolver, específicos para auxiliar a criação de uma base nacional, de fácil aplicação e monitoramento para permitir sua adoção e, consequentemente, consolidar essa base comum. É composto por dois volumes sendo que o primeiro apresenta uma concepção 
de criança, de pedagogia da Educação Infantil; a trajetória histórica do debate da qualidade na Educação Infantil, bem como, as principais tendências identificadas em pesquisas recentes no Brasil e no exterior; os desdobramentos previstos na legislação nacional para a área e consensos e polêmicas no campo. No segundo, explicitam-se, inicialmente, "as competências dos sistemas de ensino e a caracterização das instituições de educação infantil a partir de definições legais, entendendo que um sistema educacional de qualidade é aquele em que as instâncias responsáveis pela gestão respeitam a legislação vigente" (BRASIL, 2006a, 1v, p.10).

Para o documento, a criança é um sujeito social e histórico que está inserido em uma sociedade na qual partilha de uma determinada cultura. É profundamente marcada pelo meio social em que se desenvolve, mas também contribui com ele. A criança, assim, não é uma abstração, mas um ser produtor e produto da história e da cultura.

Este documento ainda aponta que olhar a criança como ser que já nasce pronto, ou que nasce vazio e carente dos elementos entendidos como necessários à vida adulta ou, ainda, a criança como sujeito conhecedor, cujo desenvolvimento se dá por sua própria iniciativa e capacidade de ação, foram, durante muito tempo, concepções amplamente aceitas na Educação Infantil até o surgimento das bases epistemológicas que fundamentam, atualmente, uma pedagogia para a infância.

O documento, também, ressalta que a interação que a criança estabelece com seus pares e os adultos é uma interação genérica, trata-se de uma interação social como espaço de constituição e desenvolvimento do ser humano.

A interação a que se referem os autores citados não é uma interação genérica. Trata-se de interação social, um processo que se dá a partir e por meio de indivíduos com modos histórica e culturalmente determinados de agir, pensar e sentir, sendo inviável dissociar as dimensões cognitivas e afetivas dessas interações e os planos psíquico e fisiológico do desenvolvimento decorrente. Nessa perspectiva, a interação social torna-se o espaço de constituição e desenvolvimento da consciência do ser humano desde que nasce. (BRASIL, 2006a, 1v, p.14)

Diante o apresentado, entendemos que assim como o RCNEI, este documento percebe a criança como sujeito social e histórico, produtora de cultura, que é influenciada pelo meio, mas que também o influencia.

O documento Política Nacional de Educação Infantil: pelo direito das crianças de zero a seis anos à Educação (BRASIL, 2006b) tem por finalidade fornecer subsídios para um processo democrático de implementação das políticas públicas para as crianças de zero a seis anos. O material é composto por apenas um volume, que apresenta as diretrizes da Política Nacional de Educação Infantil; Objetivos; Metas; Estratégias e Recomendações para a área da Educação Infantil.

Este documento mostra que, atualmente, emerge uma nova concepção de criança como criadora, capaz de estabelecer múltiplas relações, sujeito de direitos, um ser sóciohistórico, produtor de cultura e nela inserido.

Como diretrizes da política nacional de educação infantil o documento apresenta que a educação deve pautar-se pela indissociabilidade entre o cuidado e a educação. Este, também, destaca que o processo pedagógico deve considerar as crianças em sua totalidade, além de observar suas especificidades, as diferenças entre as mesmas e sua forma privilegiada de conhecer o mundo por meio do brincar. 


\section{A Concepção de Conhecimento e da Função Docente nos Documentos Oficiais do Ministério da Educação.}

Segundo o Referencial Curricular Nacional para a Educação Infantil (BRASIL, 1998), a instituição de Educação Infantil de zero a três anos deve criar um ambiente de acolhimento que dê segurança e confiança, e que garantam alguns aspectos, dentre estes: experimentar e utilizar os recursos de que dispõem para a satisfação de suas necessidades essenciais; familiarizar-se com a imagem do próprio corpo; interessar-se progressivamente pelo cuidado com o próprio corpo, executando ações simples relacionadas à saúde e higiene. Quanto ao conteúdo, estas instituições devem assegurar: reconhecimento progressivo do próprio corpo e das diferentes sensações e ritmos que produz; identificação progressiva de algumas singularidades próprias e das pessoas com as quais convive no seu cotidiano em situação de interação; realização de pequenas ações cotidianas ao seu alcance para que adquira maior independência; participação em brincadeiras de esconder e achar e de imitação; participação e interesse em situações que envolvam a relação com o outro, dentre outras.

O educar, no RCNEI, na Educação Infantil significa o favorecimento de situações de cuidado, brincadeiras e aprendizagens orientadas de forma integrada, a fim de que possam contribuir para o desenvolvimento das capacidades infantis de relação interpessoal:

[...] de ser e estar com os outros em uma atitude básica de aceitação, respeito e confiança, e o acesso, pelas crianças, aos conhecimentos mais amplos da realidade social e cultural. Neste processo, a educação poderá auxiliar o desenvolvimento das capacidades de apropriação e conhecimento das potencialidades corporais, afetivas, emocionais, estéticas e éticas, na perspectiva de contribuir para a formação de crianças felizes e saudáveis (BRASIL, 1998, 1v, p. 23).

Acerca do professor temos que este deve considerar como ponto inicial para a sua ação educativa os conhecimentos que as crianças possuem, advindos das mais variadas experiências sociais, afetivas e cognitivas a que estão expostos. Os assuntos trabalhados com as crianças devem guardar relações específicas com os níveis de desenvolvimento das crianças em cada grupo e faixa etária, respeitar e propiciar a amplitude das mais diversas experiências em relação aos eixos de trabalho propostos.

O RCNEI ainda destaca que o educador deve atentar-se, também, na organização do trabalho educativo, para alguns itens a fim de que as aprendizagens infantis ocorram com sucesso, tais como: a interação com crianças da mesma idade e de idades diferentes "em situações diversas como fator de promoção da aprendizagem e do desenvolvimento e da capacidade de relacionar-se; os conhecimentos prévios de qualquer natureza, que as crianças já possuem sobre o assunto"; a individualidade e a diversidade; o grau de desafio que as atividades oferecem e o fato de que devam ser significativas e mostradas de modo integrado para as crianças, além de deverem estar o mais próximas possíveis das práticas sociais reais; a resolução de problemas como forma de aprendizagem (BRAISL, 1998, 1v, p.30).

De acordo com os Referenciais, nas situações de aprendizagem o problema adquire um sentido importante quando as crianças buscam soluções e discutem-nas com as outras crianças. Ademais, a prática educativa deve procurar situações de aprendizagens que reproduzam contextos cotidianos. 
Acerca do "perfil profissional", o professor deve ter uma competência polivalente, o que significa, que ao professor cabe trabalhar com conteúdos de natureza diversas que abrangem desde cuidados essenciais, até conhecimentos específicos provenientes das diversas áreas do conhecimento.

A referência para a prática educativa são os âmbitos de experiências essenciais, que são compreendidos como "domínios ou campos de ação que dão visibilidade aos eixos de trabalho educativo para que o professor possa organizar sua prática e refletir sobre a abrangência das experiências que propicia às crianças" (Brasil, 1998, 1v, p. 45). O Referencial define dois âmbitos, o de Formação Pessoal e Social e o Conhecimento de Mundo.

Muitos conteúdos serão trabalhados com o intuito apenas de promover aproximações a um determinado conhecimento, de colaborar para a elaboração de hipóteses e para a manifestação de formas originais de expressão. Os conteúdos são instrumentos para analisar a realidade, não se constituindo um fim em si mesmo.

Quanto às orientações didáticas, estas são subsídios que remetem ao "como fazer", à intervenção direta do professor na promoção de atividades e cuidados relacionados com uma concepção de criança e de educação. E, os projetos dependem dos interesses das crianças; estes devem ser significativos, representar uma questão comum a todas as crianças e surgir de uma indagação da realidade.

Os Parâmetros Nacionais de Qualidade para a Educação Infantil (BRASIL, 2006a) apresentam acerca dos profissionais de Educação Infantil que estes devem possuir algumas habilidades, a saber: captar as necessidades que os bebês evidenciam antes que consigam falar; observar suas reações e iniciativas e interpretar desejos e motivações. Além disso, é preciso o estudo das diferentes áreas de conhecimento que incidem sobre essa faixa etária, com o objetivo de subsidiar de modo consistente as decisões sobre as atividades desenvolvidas, o formato de organização do espaço, do tempo, dos materiais e dos agrupamentos de crianças.

O documento Política Nacional de Educação Infantil: pelo direito das crianças de zero à seis anos à Educação (BRASIL, 2006b) destaca que, tradicionalmente, na educação de crianças de 0 a 3 anos predominam os cuidados em relação à saúde, à higiene e à alimentação, enquanto a educação das crianças de 4 a 6 anos tem sido concebida e tratada como antecipadora/preparatória para o Ensino Fundamental. Ainda ressalta que esses fatos, somados ao modelo de "educação escolar", explicam, em parte, algumas das dificuldades atuais em lidar com a Educação Infantil na perspectiva da integração entre cuidar e educar em instituições de Educação Infantil, além da continuidade com os anos iniciais do Ensino Fundamental.

Este documento, também aponta as diretrizes para a educação infantil, neste item podemos destacar que "o processo pedagógico deve considerar as crianças em sua totalidade, observando suas especificidades, as diferenças entre elas e sua forma privilegiada de conhecer o mundo por meio do brincar" (BRASIL, 2006b, p.17).

Um dos objetivos da política para a educação infantil refere-se a assegurar a valorização das professoras e professores de Educação Infantil, com a promoção da participação dos mesmos "em Programas de Formação Inicial para professores em exercício, garantindo, nas redes públicas, a inclusão nos planos de cargos e salários do magistério" (BRASIL, 2006b, p.20).

Acerca do papel dos profissionais que atuam na educação infantil temos que a formação continuada dos educadores são direitos e devem ser asseguradas a todos "pelos sistemas de ensino com a inclusão nos planos de cargos e salários do magistério" (BRASIL, 2006b, p.18). 
Este documento ainda traz algumas recomendações para as políticas na educação infantil, sendo que uma destas é referente à prática pedagógica: “[...] a prática pedagógica considere os saberes produzidos no cotidiano por todos os sujeitos envolvidos no processo: crianças, professoras e professores, pais, comunidade e outros profissionais" (BRASIL, 2006b, p.27).

Essa análise dos documentos oficiais nos permite inferir que a concepção de infância pautada no protagonismo da criança e no espontaneísmo, a função docente vista como mediadora no processo de ensino-aprendizagem e a valorização do conhecimento cotidiano em detrimento ao conhecimento sistematizado revela uma educação infantil fragmentada que não propicia um contato mais aprofundado com toda a produção humana, limitando a formação integral do indivíduo. Ademais, essas premissas estão ancoradas numa Psicologia cuja concepção de fenômeno psicológico dominante baseou-se nas ideias naturalizantes do liberalismo, que se caracterizaram por pensar o homem a partir da noção de natureza humana, que iguala os homens e exige liberdade, como condição para o desenvolvimento das potencialidades que estes possuem enquanto seres humanos (BOCK, 2004).

Desta forma, consideramos importante fazer um breve apanhado histórico acerca da consolidação da Psicologia Tradicional no Brasil para, posteriormente trazermos uma concepção de Psicologia que, de fato, contribua para a formação integral do ser humano.

\section{A Psicologia Tradicional: a consolidação das desigualdades entre as classes sociais e a hegemonia do capitalismo.}

No Brasil, segundo estudos de Mitsuko Antunes, citada por Bock (1999, p. 317318), já no período colonial é possível encontrarmos estudos sobre fenômenos psicológicos (principalmente nas áreas de Teologia, Moral, Pedagogia, Política e Arquitetura) "[...] escritos por autores de formação jesuítica, que tinham claramente a finalidade de contribuir para o controle dos indígenas. São estudos sobre emoção, auto-conhecimento [...] relacionados diretamente à questão do controle político da população colonial". Já com a vinda da Corte Portuguesa para o Rio de Janeiro, ocorre uma mudança no foco dos conteúdos psicológicos, visto que, com o aumento de pessoas nas cidades, sem condições básicas de higiene, há a proliferação de doenças infecciosas, o que desenvolve o saber médico, "[...] guiado pelas ideias da higienização e saneamento físico e moral da sociedade" (BOCK, 1999, p. 318). Desta forma, os conteúdos psicológicos se vinculam a questões médicas para caracterizar as doenças da moral, presentes nas prostitutas, nos pobres e nos loucos.

É na Primeira República que a Psicologia começa a se separar como área. Nesta fase, a Psicologia auxilia a defesa da educação, a difusão do ensino, das ideias escolanovistas, ao dar fundamentos e elementos para o desenvolvimento destes ideais. Neste sentido, crescem concepções de diferenciação das pessoas a partir de ideias de capacidades inerentes aos indivíduos. "As influências americanas tornam-se dominantes na Psicologia brasileira. As testagens psicológicas trazem, também, a enorme possibilidade de respondermos adequadamente ao desafio da modernização: o homem certo no lugar certo". (BOCK, 1999, p. 318).

Em 1962, no Brasil, houve a regulamentação da Psicologia enquanto profissão através da Lei 4119 de 27 de agosto. Em suma, podemos considerar, de acordo com Bock (1999, p. 319, grifos do autor) que o foco da Psicologia passou "[...] do controle do período colonial, para a higienização do início do século XIX, para a diferenciação no século XX" (BOCK, 1999, p.318, grifo do autor). 
Bock (2004) sinaliza que, no Brasil, a Psicologia Tradicional se comprometeu com os interesses da elite e enquanto profissão a autora afirma que:

[...] a Psicologia esteve comprometida com os interesses das elites brasileiras. Uma profissão que, quando atingiu camadas de baixo poder aquisitivo, nas empresas, nas escolas e na saúde, esteve sempre a serviço do controle, da higienização, da discriminação e da categorização que permitem melhorar a produtividade, o lucro; permitiam melhorar as condições de vida das elites brasileiras, que sempre fizeram política, nesse país, a partir exclusivamente de seus interesses (BOCK, 2004, p.02).

Após este breve histórico, centremos nosso estudo em algumas características da Psicologia Tradicional. Segundo Bock (2004) no capitalismo, com o desenvolvimento da individualização e da noção de eu, vai se tornando necessário uma ciência que estude este sentimento e este fenômeno, ou seja, a Psicologia ganha terreno:

[...] a noção de eu e a individualização nascem e se desenvolvem. A ideia de um mundo interno aos sujeitos, da existência de componentes individuais, singulares ganha força, permitindo o desenvolvimento de um sentimento de eu. Neste sentido, a possibilidade de uma ciência que estude este sentimento e este fenômeno também é resultado deste processo histórico. 'A Psicologia vai se tornando necessária' (BOCK, 2004, p.03).

Como dito anteriormente, a autora destaca que a concepção de fenômeno psicológico dominante na Psicologia Tradicional baseou-se nas ideias naturalizantes do liberalismo. "Frente às enormes desigualdades sociais do mundo moderno, o liberalismo produziu sua própria defesa, construindo a noção de diferenças individuais decorrentes do aproveitamento diferenciado que cada um faz das condições que a sociedade 'igualitariamente' lhe oferece" (BOCK, 2004, p.04).

Ademais, segundo Tuleski (2004) a Psicologia carrega em si as marcas a-históricas e conservadoras da sociedade que lhe deram origem, visto que institui-se como ciência no momento histórico no qual a burguesia, consolidada no poder, converte-se em classe reacionária. A autora também aponta que diversas correntes psicológicas permanecem herdeiras de suas raízes, caracterizando-se pelas mesmas contradições e limites, em especial, por negar o homem como ser histórico.

Bock (2004) salienta que a Psicologia Tradicional traz concepções universalizantes e naturalizantes da subjetividade. O homem e seu mundo psíquico são pensados de forma natural, com capacidades e características da espécie, e o desenvolvimento pode ocorrer caso o indivíduo seja inserido em um meio adequado. Logo, nesta vertente, o homem é responsável pelo seu sucesso ou insucesso.

Podemos perceber na Psicologia Tradicional cisões, tais como: razão x emoção, objetividade $\mathrm{x}$ subjetividade, que tem comprometido a "[...] apreensão gnosiológica do indivíduo real e concreto, alimentando equívocos no tratamento dispensado ao psiquismo humano de nefastas implicações pedagógicas" (MARTINS, 2007, p. 118).

Diante esse quadro, as pedagogias psicológicas ${ }^{1}$, que representam os ideários pedagógicos contemporâneos, por suas concepções a-históricas e abstratas de homem revelam-se incapazes de contribuir para uma prática pedagógica que, efetivamente, opere de modo positivo junto ao desenvolvimento ominilateral ${ }^{2}$ dos indivíduos. "Por consequência de seus fundamentos, tais modelos concebem o psiquismo e a subjetividade 
dos indivíduos, sua personalidade, como expressão de uma estrutura interna desligada do universo objetivo exterior" (MARTINS, 2007, p. 125).

A educação brasileira, portanto, necessita urgentemente das contribuições de uma outra Psicologia, pois, como afirma Saviani $(2004$, p. 47) “[...] na forma como a Psicologia vem sendo praticada, pondo o foco no indivíduo empírico e não no indivíduo concreto, suas contribuições resultam praticamente neutralizadas".

Saviani (2004) destaca ainda que é necessário conhecer o indivíduo concreto ${ }^{3}$, uma vez que o indivíduo empírico é o imediatamente observável, apreendido por definibilidades exteriores correspondentes à situação empírica imediata, porém, o indivíduo concreto é a síntese das múltiplas determinações, apreendido à luz de sua natureza histórico-social.

Tanamachi (2007) afirma que diversos estudos, realizados por várias correntes de pensamento que se desenvolveram na psicologia ocidental, tais como analisadas por Vigotski e o seu grupo, apresentam visões reducionistas sobre o fenômeno humano e, consequentemente, não respondem à realidade do ser humano em sua existência concreta, social e historicamente determinada.

Segundo Vygotski (1995), a Psicologia Tradicional preocupava-se com a criança e o com o desenvolvimento de suas funções psíquicas in abstracto, ou seja, desconsiderando o seu meio social e cultural; suas formas de pensamento, concepções e ideias produzidas historicamente e predominantes nesse meio.

Neste ponto, cabe um parêntese, pois diante do exposto anteriormente acerca da Psicologia Tradicional, podemos fazer um paralelo desta corrente teórica com as concepções presentes nos Documentos Oficiais do Ministério da Educação. Após a análise desses documentos percebemos que há uma fragmentação e naturalização da educação, além da negação do homem como ser histórico e social, características fundamentais da Psicologia Tradicional.

O verdadeiro significado da crise da Psicologia, segundo Vigotski (1991), só será descoberto através da elevação, desde o plano da discussão crítica do sistema até a altura da investigação básica, com a ajuda dos métodos da ciência geral e assim será possível perceber a estrutura subjacente na atual confrontação de ideias e posições, a qual é condicionada pelo próprio desenvolvimento da ciência e pela natureza da realidade a ser estudada na fase de seu conhecimento.

A crítica que Vigotski (2001) fazia à velha psicologia era na forma como esta considerava os processos psíquicos superiores, uma vez que estes eram tratados como soma ou cadeia de processos elementares. Para Vigotski (1996) a tarefa fundamental da análise em Psicologia não é decompor o todo psicológico em partes ou fragmentos, contudo evidenciar do conjunto psicológico integral determinados traços e momentos que conservam a prioridade do todo.

Segundo Tuleski (2002) a superação da velha psicologia só seria possível com a elaboração de uma nova Psicologia sustentada em uma perspectiva histórica na relação homem-natureza, de modo que, o homem fosse o produto e produtor de si e da própria natureza. Isso significaria o abandono de relações mecânicas, empíricas e simples entre os fenômenos, para uma nova compreensão do homem como um ser complexo e dinâmico.

Nesta perspectiva, Vigotski, buscou, então, aprofundar seus estudos em uma Psicologia que se voltasse para o indivíduo como um todo e não fragmentado, que considerasse o histórico e o social num movimento dialético para o desenvolvimento humano. No II Congresso de Psiconeurologia, em Leningrado, no ano de 1924 Vigotski foi convidado para trabalhar no Instituto de Psicologia da Universidade de Moscou. (SHUARE, 1990). 
Segundo Leontiev (1978) uma nova etapa no estudo do problema do determinismo sócio-histórico do psiquismo humano foi marcada pelos trabalhos de L. S. Vigotski. Ele foi o primeiro, em 1927, a exprimir a tese de que a démarche histórica devia se tornar o princípio diretor da edificação da Psicologia do homem. Este autor efetuou a crítica teórica das concepções biológicas naturalistas do homem, opondo-lhes à sua teoria do desenvolvimento histórico e cultural. Além disso, Vigotski introduziu, na investigação psicológica concreta, a ideia da historicidade da natureza do psiquismo humano e a da reorganização dos mecanismos naturais dos processos psíquicos no decurso da evolução sócio-histórica e ontogenética. Ele interpretava esta reorganização como o resultado necessário da apropriação pelo homem dos produtos da cultura humana no decurso dos seus contatos com os seus semelhantes. Com efeito, as investigações de Vigotski partiam de duas hipóteses: as funções psíquicas do homem são de caráter mediatizado e os processos interiores intelectuais provêm de uma atividade inicialmente exterior, interpsicológica.

Seguindo essa linha de raciocínio, apresentaremos a concepção de desenvolvimento e ensino que acreditamos pautar-se no desenvolvimento integral da criança, visando contribuir para o debate acerca do papel que a educação infantil deve exercer na formação das crianças. Para tal tarefa nos deteremos à Psicologia Histórico-Cultural, uma vez que, nesta linha teórica, as concepções de infância, professor e conhecimento diferem do exposto anteriormente, já que considera o desenvolvimento integral do indivíduo. Nessa vertente o educador assume a função de explicitar à criança os traços da atividade humana sustentados nos objetos da cultura, transmitindo assim, a esta os resultados do desenvolvimento histórico.

\section{Psicologia Histórico-Cultural: concepção de desenvolvimento infantil e ensino para a promoção do desenvolvimento integral humano.}

Para a Psicologia Histórico-Cultural, o papel do professor, enquanto agente ativo do processo de ensino-aprendizagem da criança é crucial, pois, este, diferentemente do discurso presente nos documentos oficiais, não é um mero mediador no processo de aprendizagem da criança pequena. Esta é uma perspectiva do desenvolvimento infantil que contempla aspectos históricos e sociais da criança e não só fatores biológicos, ressaltando que este é um processo histórico-dialético (VYGOTSKY, 1995; LEONTIEV, 1978; ELKONIN, 1987).

A Psicologia Histórico-Cultural ${ }^{4}$ surgiu no início do século $\mathrm{XX}$ na ex-União Soviética (URSS), no contexto da Rússia pós-revolucionária. Esta corrente tem como principais referências ${ }^{5}$ Liev Semiónovich Vygotsky (1896-1934), Alexis Nikoláevich Leontiev (1903-1979) e Alexander Románovich Luria (1902-1977), que junto com representantes como Daniíl Borísovich. Elkonin (1904-1984); Vasili Vasílievich Davidov (1930-1998); Alexandr Vladimirovich Zaporozhets (1905-1981); Piotr Iakovlevich Galperin (1902-1988) e Lidia Ilínichna Bozhovich (1908-1981) compõe a chamada Escola de Vigotski.

Vigotski (1995) entendia que método e objeto de investigação devem ser ajustados de forma adequada e por isso, o estudo dos processos psíquicos superiores, especificamente, humanos, principal objeto de estudo da psicologia vigotskiana, exigia a formulação de um método de investigação próprio. Ademais, o autor era contrário à análise fenomenológica ou descritiva em psicologia, considerando que esta “[...] toma o fenômeno tal como aparece externamente e supõe com toda a ingenuidade que o aspecto exterior ou a 
aparência do objeto coincide o nexo real, dinâmico-causal que constitui sua base" (VIGOTSKI, 1995, p. 103).

Vale destacar que Vigotski (1995), também, defendia uma análise psicológica explicativa, que mostrasse os nexos dinâmicos-causais determinantes da origem e do desenvolvimento dos fenômenos.

Para Shuare (1990), a psicologia histórico-cultural diferencia-se de outros sistemas científicos pela relação que estabelece com a filosofia, visto que, esta busca em sua concepção filosófica determinada, a saber, o materialismo histórico dialético, os marcos metodológicos no interior dos quais se deve desenvolver a investigação científica.

A tarefa da psicologia histórico-cultural consiste, segundo Bozhovich (1976), na investigação das particularidades psicológicas da criança segundo sua idade, que não se limitam à característica dos processos psíquicos isolados e sim, pelo contrário, revele a estrutura da personalidade integral da criança em seu processo de formação e desenvolvimento.

\section{O Desenvolvimento Infantil e o Processo Educativo na Perspectiva Histórico- Cultural.}

De acordo com Pasqualini (2006, p. 117), Vigotski, Leontiev e Elkonin concebiam o desenvolvimento infantil como fenômeno histórico e dialético, que "[...] não é determinado por leis naturais universais, mas encontra-se intimamente ligado às condições objetivas da organização social e não se desenrola de forma meramente linear, progressiva e evolutiva, mas compreende saltos qualitativos, involuções e rupturas".

Blonski (apud ELKONIN, 1987, p. 105) assinala o caráter historicamente variável dos processos de desenvolvimento psíquico e o surgimento, no curso da história, de novos períodos da infância. "[...] a infância não é um fenômeno eterno, invariável: é diferente em cada estágio do desenvolvimento do mundo animal; é diferente também em cada estágio do desenvolvimento histórico da humanidade".

Faz-se necessário superar a visão idealista do desenvolvimento psicológico. Como Vygotsky afirmou nos anos de 1930, segundo Elkonin (1999), é imprescindível estudar a afetividade e o intelecto como unidade dinâmica e não é mais pertinente abordar o desenvolvimento psíquico como um mecanismo adaptativo do comportamento. A concepção de Piaget é clara nesse sentido ao abordar o desenvolvimento intelectual separado da esfera afetiva e das necessidades. A principal deficiência desta concepção é a impossibilidade de explicar as passagens de um estágio de desenvolvimento intelectual a outro. Diante disso, o mais fácil é atribuir à maturação ou outras forças externas com relação ao processo de desenvolvimento psíquico.

Segundo Leontiev (1987), a criança no curso de seu desenvolvimento penetra ativamente no mundo das relações humanas que a rodeia, assimilando as funções sociais das pessoas, as normas e regras de comportamento socialmente elaboradas. Esta concreção, inicialmente obrigatória - caráter ativo da forma em que a criança assimila os processos superiores de comportamento humano - exige que as tarefas que o educador lhe sugere tenham conteúdo e que a vinculação entre o que a criança deve fazer e aquilo por que atua e as condições de sua ação não sejam formais nem convencionais.

Elkonin (1987) mostra que sem a superação do dualismo e do paralelismo, não se pode compreender o desenvolvimento psíquico como processo único e integral. No fundamento deste dualismo e paralelismo se encontra o enfoque naturalista do desenvolvimento infantil, característico para a maioria das teorias estrangeiras. 
Com relação à função docente no desenvolvimento infantil, uma evidência da importância do educador neste processo está, segundo Leontiev (1987), na formação da subordinação de motivos, ao começo, na comunicação com o educador, ou seja, na situação imediatamente social, e, posteriormente, torna-se possível, também, em situações nas quais a criança atua de forma autônoma.

$\mathrm{O}$ autor também destaca que a partir destas ligações, que unem entre si processos orientados a um fim, porém isolados ${ }^{6}$ se começa a tecer a trama geral sobre, cujo fundo, paulatinamente, se separam as principais linhas de sentido da atividade do homem, as quais caracterizam sua personalidade. A formação da psique na idade pré-escolar constitui um processo muito complexo e diverso.

Segundo Elkonin (1987), o desenvolvimento da criança é a permanente passagem de uma escala evolutiva a outra, estando esta ligada à mudança e a estruturação da personalidade da criança. Estudar o desenvolvimento infantil significa "[...] estudar a passagem da criança de um período evolutivo a outro e a mudança de sua personalidade dentro de cada período evolutivo que tem lugar em condições histórico-sociais concretas" (ELKONIN, 1987, p. 106).

Vygotski (1995, p.156) acrescenta que o desenvolvimento infantil é marcado por mudanças bruscas:

[...] o desenvolvimento não se produz pela via de mudanças graduais, lentas, por uma acumulação de pequenas peculiaridades que produzem em seu conjunto e ao final alguma mudança importante. [...] observamos a existência de mudanças bruscas e essenciais no próprio tipo de desenvolvimento, nas próprias forças motrizes do processo.

Blonski (apud ELKONIN, 1987), era contrário às ideias puramente evolucionistas sobre o curso do desenvolvimento infantil. Considerava que este era, sobretudo, um processo de transformações qualitativas acompanhadas de crises ${ }^{7}$ e saltos. Sendo que, estas mudanças:

[...] podem transcorrer em forma bruscamente crítica ou gradual. Convencionamos em chamar épocas e estágios aos períodos da vida infantil separados por crises, umas mais marcadas (épocas) e outras menos marcadas (estágios). Também convencionamos em chamar fases aos momentos da vida infantil não separados entre si bruscamente (ELKONIN, 1987, p. 106).

O desenvolvimento psíquico na infância é influenciado pela educação e ensino estabelecidos por adultos, que organizam a vida da criança, criam condições específicas e transmitem-lhes a experiência social acumulada pela humanidade. Segundo Elkonin (1969) ao receber essa experiência a criança adquire um círculo de conhecimentos encaminhados por gerações precedentes, aprende as habilidades elaboradas socialmente e as formas de conduta da sociedade. Essas experiências são responsáveis pela formação de distintas capacidades.

Com relação à aquisição de conhecimentos, Elkonin (1969) enfatiza que nem todas as formas de apreensão desenvolvem as capacidades e a atividade intelectuais. Além disso, nem sempre a observação das regras de conduta atesta o desenvolvimento das características correspondentes à personalidade infantil. Ao contrário, frequentemente, os conhecimentos assimilados formalmente não servem como guia para a ação, por isso são pouco utilizados na prática e, consequentemente não influenciam o desenvolvimento intelectual das crianças. Muitas vezes as regras de conduta cumprem-se apenas de forma 
externa e quando tem condições exatamente determinadas. $\mathrm{O}$ autor ainda destaca que o desenvolvimento da psique não reflete de maneira automática tudo o que atua sobre a criança. $\mathrm{O}$ efeito dos agentes externos, a influência da educação e do ensino, depende de como se realiza esta influência e da forma como esta recai no terreno formado anteriormente.

Elkonin (1969), assim, indica que o adulto ensina à criança como manejar as coisas, e no curso da aprendizagem esta não somente conhece as qualidades dos objetos, como também assimila a experiência da humanidade para utilizá-los na prática. $\mathrm{O}$ autor utiliza com exemplo o estudo da gramática em que a criança assimila as regras e as leis determinadas do idioma além de desenvolver capacidade de pensamento abstrato.

Acerca da relação entre desenvolvimento e aprendizagem, Vigotskii (2006) apresenta e agrupa as teorias mais importantes em três categorias fundamentais. A primeira implica numa completa independência entre o processo de desenvolvimento e o de aprendizagem e chega até a postular uma nítida separação de ambos os processos no tempo. Nesta categoria, invariavelmente, o curso do desenvolvimento precede o da aprendizagem, ou seja, a aprendizagem segue sempre o desenvolvimento. A segunda categoria afirma, pelo contrário, que a aprendizagem é desenvolvimento, segundo James (apud VIGOTSKII, 2006, p.105), "a educação pode ser definida como a organização de hábitos de comportamento e de inclinações para a ação". Nesta categoria constatamos que o desenvolvimento vê-se reduzido a uma simples acumulação de reações. Por fim, na terceira percebemos que há uma tentativa de conciliação dos extremos das teorias anteriormente apresentadas, o que supõe uma teoria dualista do desenvolvimento. Desta forma, de um lado, o processo de desenvolvimento está concebido como independente do de aprendizagem, porém de outro esta mesma aprendizagem considera-se coincidente com o desenvolvimento.

Vigotskii (2006, p. 109) destaca que a aprendizagem da criança tem início anteriormente à aprendizagem escolar, ou seja, "toda a aprendizagem da criança na escola tem uma pré-história". Além disso, enfatiza que, primeiramente, devemos compreender a relação entre aprendizagem e desenvolvimento em geral e, posteriormente, as características específicas desta inter-relação na idade escolar. "É uma comprovação empírica, frequentemente verificada e indiscutível, que a aprendizagem deve ser coerente com o nível de desenvolvimento da criança" (VIGOTSKII, 2006, p.111).

$\mathrm{O}$ autor afirma que para se definir a efetiva relação entre desenvolvimento e aprendizagem, é necessário determinar, no mínimo, dois níveis de desenvolvimento infantil: desenvolvimento efetivo e desenvolvimento potencial da criança. Entendemos o primeiro como "o nível de desenvolvimento das funções psicointelectuais da criança que se conseguiu como resultado de um específico processo de desenvolvimento já realizado" (VIGOTSKII, 2006, p. 111). Em relação ao segundo temos que "a diferença entre o nível das tarefas realizáveis com o auxílio dos adultos e o nível das tarefas que podem desenvolver-se com uma atividade independente define a área de desenvolvimento potencial da criança" (VIGOTSKII, 2006, p.112). O autor também apresenta que a zona de desenvolvimento potencial da criança ${ }^{8}$ permite-nos analisar o processo de desenvolvimento e maturação já produzidos, até o momento, bem como os processos que ainda estão ocorrendo e se desenvolvendo, além de determinar os futuros passos e a dinâmica do desenvolvimento infantil.

Vigotskii (2006) considera que a aprendizagem não é em si mesma, desenvolvimento, porém, uma correta organização da aprendizagem da criança conduzirá ao desenvolvimento mental, ativará todo um grupo de processos de desenvolvimento, sendo que esta ativação não poderia produzir-se sem a aprendizagem. Por isso, "[...] a 
aprendizagem é um momento intrinsecamente necessário e universal para que se desenvolvam na criança essas características humanas não-naturais, mas formadas historicamente" (VIGOTSKII, 2006, p. 115).

Dessa forma, o papel do trabalho educativo deve operar precisamente na atividade da criança e em sua consciência. Leontiev (2006) enfatiza que o educador opera sobre a atividade da criança e determina o desenvolvimento de seu psiquismo. Consideramos tal afirmação relevante, uma vez que, se opõe diretamente à concepção do educador como alguém que se limita a seguir as crianças, como proposto nos documentos do Ministério da Educação.

Como nos mostra Saviani (2005), não podemos pensar o papel do educador como alguém que apenas estimula e acompanha a criança em seu desenvolvimento, porém como alguém que transmite à criança os resultados do desenvolvimento histórico, que explicita os traços da atividade humana objetivada e cristalizada nos objetos da cultura.

Acerca dos educadores, Davidov (1988) afirma que estes devem: 1) realizar uma análise do material fático com o fim de descobrir neste certa relação geral que apresenta uma vinculação sujeita à lei com as diferentes manifestações deste material, ou seja, a construção da abstração e da generalização substanciais; 2) fazer a dedução, sobre a base da abstração e a generalização, das relações particulares do material dado e sua união (síntese) em certo objeto integral, quer dizer, a construção de sua célula e do objeto mental concreto; 3) ter o domínio, neste processo analítico-sintético, do procedimento geral de construção do objeto estudado.

O autor enfatiza que o conteúdo dos assuntos deve favorecer a formação, nos escolares, do pensamento teórico, cujas leis estão postas pela dialética materialista como lógica e teoria do conhecimento e pela psicologia que nesta se apóia. Não devemos nos esquecer de que nos escolares o pensamento teórico se forma durante a realização da atividade de estudo.

Diante do exposto acreditamos que ao utilizarmos os pressupostos da Psicologia Histórico-Cultural, poderemos contribuir para a formação integral das crianças, respeitando a faixa etária e as características peculiares da infância.

\section{Considerações Finais}

Neste ensaio, portanto, buscamos analisar a concepção de infância, conhecimento e função docente presente nos documentos oficiais do Ministério da Educação, trazendo o modelo de Psicologia dominante neste cenário. Ao final, tentamos mostrar que a partir dos pressupostos da Psicologia Histórico-Cultural podemos encontrar um horizonte de problematização das práticas que tomam a criança e seu processo de desenvolvimento de forma abstrata e alheia às determinações sócio-culturais. Para tal, apresentamos os principais pressupostos dessa corrente e a concepção de desenvolvimento e ensino para alguns dos pensadores dessa perspectiva. Nossa reflexão caminha no sentido de pensarmos o quanto estamos desfavorecendo a formação infantil, deixando de enriquecê-la quando realizamos um trabalho pautado no espontaneísmo, no protagonismo da criança e na falta de intencionalidade do educador em suas práticas educativas. Além disso, destacamos, a importância do professor e de um trabalho docente intencional. Será que devemos continuar coniventes com a adoção de políticas públicas que desvalorizem o profissional de educação infantil e que desconsiderem o desenvolvimento integral da criança? Se quisermos mudanças nas políticas públicas brasileiras e nas práticas dentro das instituições de educação infantil, devemos refletir sobre qual educação estamos oferecendo às nossas crianças. 
Faz-se, imprescindível que pensemos a educação infantil como a articulação entre uma tríade: formação docente, práticas educativas e políticas públicas, tendo como suporte o materialismo histórico-dialético. Kuenzer (1999) apresenta que a função do educador é ensinar, transmitir o saber sistematizado e que para isso ocorra é preciso que haja intencionalidade no trabalho do professor. Consideramos que se faz necessário pensarmos nesse profissional como um intelectual; um profissional responsável pela formação intencional da criança.

Ademais, pensar a concepção de infância, trabalho docente e aquisição de conhecimento, considerando a Psicologia Histórico-Cultural demanda: planejamento; formação docente; interdisciplinaridade entre as diversas áreas do conhecimento; dentre outros. Ou seja, é necessário um trabalho sério para a construção de um currículo para a educação infantil, tendo como eixo o ensino para a promoção do desenvolvimento integral infantil.

\section{Referências}

BOCK, A. M. B. A perspectiva histórica da subjetividade: uma exigência para la psicologia atual. Psicología para a América Latina, n.1, fev. 2004. Disponível em: <http://www.psicolatina.org>. Acesso em: 20 fev. 2008.

A Psicologia a caminho do novo século: identidade profissional e compromisso social. Estudos de Psicologia, Natal, v. 4. n. 2, p. 315-329, 1999.

BOZHOVICH, L. I. La personalidad y su formación en la edad infantil: investigaciones psicológicas. Traducido directamente del ruso por Toste Muñiz. Havana: editorial pueblo y educación, 1976.

BRASIL. Ministério de Educação e do Desporto. Secretaria de Educação Básica. Parâmetros Nacionais de Qualidade para a Educação Infantil. Brasília, DF: MEC, $2006 \mathrm{.}$ 2.v.

Ministério de Educação e do Desporto. Secretaria de Educação Básica. Política Nacional de Educação Infantil: pelo direito das crianças de zero a seis anos à educação. Brasília, DF: 2006b.

Ministério de Educação e do Desporto. Referencial Curricular Nacional para Educação Infantil. Brasília, DF: MEC, 1998. 3.v.

DAVIDOV, V. La enseñanza escolar y el desarrollo psíquico. Traducido del ruso por Marta Shuare. Moscou: Editorial Progresso, 1988.

ELKONIN, D. B. Toward the problem of stages in the mental development of children. Journal of Russian and East European Psychology. New York, v. 37. n. 6, p. 11-30, nov/dez. 1999.

Sobre el problema de la periodización del desarrollo psíquico en la infancia. In: DAVIDOV, V; SHUARE, M. (Org.). La Psicologia Evolutiva y Pedagógica en la URSS: antologia. Moscou: Editorial Progresso, 1987. p. 104-124. 
- Desarrollo psíquico de los niños. In: Smirnov, A. A; (Org.). Psicologia. Traducción por Florencio Villa Landa. 3.ed. México: Editorial Grijalbo, 1969. p. 493-560.

KUENZER, A. Z. As políticas de formação: a constituição da identidade do professor sobrante. Educação e Sociedade, Campinas, Ano XX, n. 68, p. 163-183, dez. 1999.

LEONTIEV, A. N. Uma contribuição à teoria do desenvolvimento da psique infantil. In: VIGOTSKII, L. S; LURIA, A. R; LEONTIEV, A.N. Linguagem, desenvolvimento e aprendizagem. Tradução de Maria da Panha Villalobos. São Paulo: Ícone, 2006. p. 59-84.

El desarrollo psíquico del niño en la edad preescolar. In: DAVIDOV, V; SHUARE, M. (Org.). La Psicologia Evolutiva y Pedagógica en la URSS: antologia. Moscou: Editorial Progresso, 1987. p. 57-70.

O desenvolvimento do psiquismo. Lisboa: Livros Horizonte, 1978.

MARTINS, L. M. Algumas reflexões sobre o desenvolvimento omnilateral dos educandos. In: MEIRA, M. E; FACCI, M. G. D. (Org.). Psicologia Histórico-Cultural: contribuições para o encontro entre a subjetividade e a educação. São Paulo: Casa do Psicólogo, 2007. p.117-134.

PASQUALINI. J. C. Contribuições da Psicologia Histórico-Cultural para a educação escolar de crianças de 0 a 6 anos: desenvolvimento infantil e ensino em Vigotski, Leontiev e Elkonin. 2006. 205f. Dissertação (Mestrado em Educação Escolar) - Faculdade de Filosofia, Ciências e Letras, Universidade Estadual Paulista, Araraquara, 2006.

SAVIANI, D. Pedagogia Histórico-Crítica: primeiras aproximações. 9. ed. Campinas: Autores Associados, 2005. (Coleção educação contemporânea).

Perspectiva marxiana do problema subjetividade-intersubjetividade. In: DUARTE, N. (Org.) Crítica ao fetichismo da individualidade. Campinas: Autores Associados, 2004. p. 21-52.

SHUARE, M. La psicologia soviética tal como yo la veo. Moscou: Editorial Progresso, 1990.

TANAMACHI, E. de. R. A Psicologia no contexto do materialismo histórico dialético: elementos para compreender a Psicologia Histórico-Cultural. In: MEIRA, M. E; FACCI, M. G. D. (Org.). Psicologia Histórico-Cultural: contribuições para o encontro entre a subjetividade e a educação. São Paulo: Casa do Psicólogo, 2007. p. 63-92.

TULESKI, S. C. Reflexões sobre a gênese da Psicologia Científica. In: DUARTE, N. (Org.) Crítica ao fetichismo da individualidade. Campinas: Autores Associados, 2004. p. 121-143.

Vygotski: a construção de uma psicologia marxista. Maringá: Edum, 2002. 
VIGOTSKII, L. S. Aprendizagem e desenvolvimento intelectual na idade escolar. In: VIGOTSKII, L. S; LURIA, A. R; LEONTIEV, A.N. Linguagem, desenvolvimento $e$ aprendizagem. Tradução de Maria da Panha Villalobos. São Paulo: Ícone, 2006. p.103118.

A construção do pensamento e da linguagem. Tradução de Paulo Bezerra. São Paulo: Martins Fontes, 2001.

. Obras Escogidas. Madri: Visor, 1996. Tomo IV.

. Obras Escogidas. Madri: Visor, 1995. Tomo III.

Obras Escogidas. Madri: Visor, 1991. Tomo I.

\section{Notas}

1. Segundo Martins (2007 apud MIRANDA, 2000, p. 24) as pedagogias psicológicas estão ancoradas em modelos psicológicos segundo os quais o desenvolvimento e a aprendizagem são conquistas particulares do aluno mediante sua ação e auxiliado pelo professor, num processo pelo qual a educação "adequa-se" cada vez mais às exigências sociais impostas pela globalização da economia.

2. “[...] um desenvolvimento total, completo, multilateral, em todos os sentidos das faculdades e das forças produtivas, das necessidades e da capacidade de sua satisfação" (MANACORDA, 2000, p. 7879).

3. Segundo Martins (2007, p.124) para se conhecer efetivamente o que Saviani denomina indivíduo concreto, é necessária uma psicologia que, superando os limites do pensamento dicotômico lógicoformal, contribua para o conhecimento do homem em sua totalidade, dado próprio à Psicologia SócioHistórica.

4. Esta corrente teórica também tem outras denominações, tais como: Psicologia Sócio-Histórica, Teoria Histórico-Cultural ou Teoria da Atividade.

5. A biografia dos autores da Escola de Vigotski está presente ao final da obra: DAVIDOV, V; SHUARE, M. (Org.). La Psicologia Evolutiva y Pedagógica en la URSS: antologia. Moscou: Editorial Progresso, 1987.

6. Esta união ocorre de tal modo que os processos orientados a um fim entram numa relação de subordinação a outros

7. Na psicologia infantil soviética e estrangeira se tem acumulado um importante material que dá base para identificar duas bruscas passagens no desenvolvimento psíquico das crianças. Trata-se, em primeiro lugar, da passagem da primeira infância à idade pré-escolar, conhecido na literatura como crise dos três anos. Em segundo lugar, está a passagem da idade escolar jovem a idade adolescente, que na literatura denomina-se crise da maturação sexual (ELKONIN, 1987).

8. Defini-se zona de desenvolvimento potencial da criança, segundo Vigotskii (2006, p.112) como "o que uma criança é capaz de fazer com o auxílio dos adultos".

\footnotetext{
${ }^{1}$ Doutoranda do Programa de Pós Graduação em Educação da Universidade Federal de São Carlos - UFSCar e bolsista da FAPESP.

${ }^{2}$ Professora do Depto de Educação da Universidade Federal de São Carlos - UFSCar
} 